\title{
Prevalence of Tobacco Use and Efforts for Tobacco Control in The Democratic People's Republic of Korea
}

Heeje Lee ( $\nabla$ heejelee@hotmail.com )

University of California Berkeley https://orcid.org/0000-0002-0021-3079

Minah Kang

Ewha Womans University

Sangchul Yoon

Yonsei University College of Medicine

Kee B. Park

Harvard Medical School

\section{Research}

Keywords: mocratic People's Republic of Korea (DPRK), tobacco use, tobacco control, government

Posted Date: August 5th, 2021

DOI: https://doi.org/10.21203/rs.3.rs-761614/v1

License: () (1) This work is licensed under a Creative Commons Attribution 4.0 International License. Read Full License 


\section{Abstract}

Tobacco use is one of the main public health concerns as it causes multiple diseases. The Democratic People's Republic of Korea (DPRK) is one of the 168 signatory countries of the World Health Organization (WHO) member states agreed to adopt the WHO Framework Convention of Tobacco Control (FCTC). However, there is lack of information regarding the tobacco use in the DPRK and the government's efforts for tobacco control. The aim of the study was to find the prevalence of tobacco use among the DPRK people and the government's efforts to control tobacco use among its population, through literature review combined with online media content analysis. In 2020, the prevalence of tobacco smoking in males of 15 years and older was $46.1 \%$, whereas that in females was zero. The online media contents showed the DPRK government's stewardship to promote population health by controlling tobacco use. Furthermore, the DPRK government has taken steps to implement the mandates of the FCTC including introduction of new laws, promotion of research, development of cessation aids, as well as public health campaigns.

\section{Background}

Ever since the first epidemiological studies on the harmful health effects of tobacco have been conducted in as early as 1930 s, ${ }^{1,2}$ we now know that tobacco use causes multiple diseases such as lung cancer, liver cancer, breast cancer, chronic obstructive pulmonary disease, asthma, cardiovascular diseases, and more. $^{3}$ The adverse health effects of tobacco use spares no organs of the body.

In 2003, the World Health Organization (WHO) member states agreed to adopt the WHO Framework Convention of Tobacco Control (WHO FCTC). ${ }^{4}$ The goal of this historical treaty was to provide evidence-based approach to reduce the prevalence of tobacco use among the population and encourage the participating countries to keep high levels of compliance. The signatory countries are required to report every other year on the prevalence data of tobacco use and progress in implementing tobacco control policies in the country so that they could compare and learn from each other's experience.

The Democratic People's Republic of Korea (DPRK), also known as North Korea, is one of the 168 signatory countries of the WHO FCTC and it has been reporting on the progress since 2012. From the global health point of view, reliable data and information is fundamental to understanding health condition of the target population and the effectiveness of any interventions. Although there have been previous publications that reported prevalence of smoking and its health implication in the $\mathrm{DPRK}_{,}^{5-8}$ the quantity of the available information is significantly less than those from other countries. The relative lack of information regarding the tobacco use in the DPRK and the government's efforts for tobacco control makes it difficult to have a clear view on the current situation of the country and to optimally promote international cooperation against harmful effects of tobacco use. Lately, printed materials and web documents and videos from the DPRK are available in the format of online media providing a valuable source of information regarding the tobacco use and control in the DPRK.

Therefore, the aim of the study is to answer two questions through literature review combined with online media contents analysis: 1) what is the prevalence of tobacco use among the DPRK people? 2) what has been done in the DPRK to control tobacco use among its population?

\section{Methods}

\section{Search for publications in English}

We performed online searches with keywords: North Korea, Democratic People's Republic of Korea, smoking, tobacco. Inclusion and exclusion criteria are as follows:

Inclusion criteria: a) a full text article in a peer review journal, and b) a publication from an organization containing data and information regarding tobacco use and control in the DPRK.

Exclusion criteria: a) an article in a newspaper or a personal blog, b) a review article, c) an article of which study subjects were not residing in the DPRK, and d) an article of which full text is not available.

The articles and publications that met requirements of the inclusion criteria were kept for review.

\section{Search for the DPRK publications in Korean}

The Information Center on North Korea, an institution under the Ministry of Unification, Republic of Korea (South Korea) maintains multiple periodic DPRK journals. The list of the journals and titles of articles, mostly in Korean, are available on the center's website. It is noteworthy that all the authors are fluent in

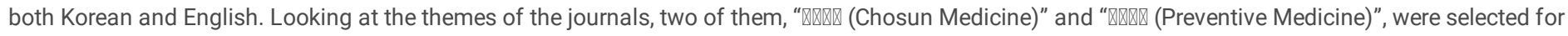
further search. To find the recent materials and due to limited availability, the search was narrowed down to those published from 2009 to 2018 . All the titles of articles published in the journals were reviewed online and the relevant articles were selected. The definition of the relevant article here is that its title included the Korean word that corresponded to "tobacco", "smoking cigarette", or "smoking cessation" in English. One of the authors visited the center to make copies of the full text for further analysis. The articles that were related to the research questions were kept for review. We did not strictly apply the inclusion and exclusion criteria above for this category to collect as many materials directly from the DPRK as possible.

\section{Search for online media in Korean created by the DPRK}

We found several media websites operated by the DPRK government: uriminzokkiri.com, dprktoday.com, and dprkmedia.net. Using the keywords in Korean that corresponded to "tobacco", "smoking cigarette", "smoking cessation" in English, we found multiple web articles and videos that were related to the study 
questions. They were saved in a local computer for review.

\section{Search for other materials}

We performed online search to find any other materials that were relevant to the research questions. When the acceptable material was found, it was saved in a local computer for review.

We began the searches on April 04, 2021 and completed on May 07, 2021. After collecting all available materials as above, we reviewed the contents to answer the research questions.

\section{Results}

The following articles, materials, videos were included for review: 2 scientific articles in English in peer review journals, 5,810 scientific articles in Korean in the DPRK journals, ${ }^{9-18} 26$ web documents in Korean, ${ }^{19-44} 4$ videos in Korean, ${ }^{45-48} 4$ WHO FCTC reports in English, ${ }^{49-52}$ a WHO report on the global tobacco epidemic in English, ${ }^{7}$ a DPRK Tobacco Control Law in English, ${ }^{53}$ and a DPRK Tobacco Control Law in Korean. ${ }^{54}$

The latest WHO FCTC report in 2020 showed that the prevalence of tobacco smoking in males of 15 years and older was $46.1 \%$. As most of them (83.3\%) smoked daily, the prevalence of male daily smokers was $38.4 \%$. The prevalence of tobacco smoking in females was always zero. According to the report, smoking cigarettes was the only method of tobacco use in the DPRK.

Notably, multiple sources showed various activities that were required by WHO FCTC are being implemented in the DPRK. The government enacted the tobacco control law in 2005 and has amended several times to strengthen the law. ${ }^{53,54}$ In fact, the first decree to restrict smoking among population was issued as early as in 1985 and became the basis of the nationwide governmental tobacco control. ${ }^{55}$ The DPRK has submitted the WHO FCTC report in $2012,{ }^{49}$ $2014,{ }^{50} 2018,{ }^{51}$ and $2020 .{ }^{52}$ Other government efforts to discourage people from smoking were reported on the online media. The online version of the DPRK newspapers wrote about several anti-smoking topics: negative health effects of smoking, ${ }^{19}$ anti-smoking conferences, ${ }^{20,21,24,27,33}$ government-led antismoking movement, ${ }^{22,26,28,29,31,32,37,38,40,41,44}$ development of smoking cessation products, ${ }^{23,25,30}$ and anti-smoking law. ${ }^{39,42,43}$ Surprisingly, there were three news articles that introduced the native habitat of high quality domestic tobacco plant. ${ }^{34-36}$ There were four relevant videos produced in the DPRK which were openly available. They were about negative effects of smoking, ${ }^{45}$ development of the smoking-cessation product, ${ }^{46}$ and reasons and benefits of quitting smoking. ${ }^{47,48}$ Domestically published research were about development and evaluation of smoking-cessation products, ${ }^{11,12,17,18}$ anti-smoking public health intervention, ${ }^{15}$ and negative health effects of smoking. ${ }^{10,13,14,16}$ There was a review article about the worldwide anti-smoking movement in another domestic scientific journal. ${ }^{9}$

\section{Discussion}

The latest self-reported prevalence of tobacco use among the DPRK males was $46.1 \%$ in 2020 . It is not clear whether the new survey was done after the previous report because almost all prevalence data in 2020 were exactly the same as those reported in 2018 . The prevalence of daily smoking among the DPRK male was $38.4 \%$ in both 2018 and 2020 reports. In an article that reported the age-adjusted prevalence of daily smoking among males in 2015 , the DPRK's prevalence was $36.7 \%$, as opposed to the global average $25.0 \%{ }^{5}$ According to the WHO FCTC reports, the prevalence of daily smoking among the DPRK males remains high with slight reduction over time after the government has made multiple efforts to control tobacco use (Fig. 1). It is noteworthy that the Institute for Health Metrics and Evaluation (IHME) data map showed relatively high prevalence of daily smoking among males in the Eastern Asia, Central Asia, Southeastern Asia, and Eastern Europe regions. ${ }^{6}$ The prevalence of some selected countries from those regions is shown in Table 1. In some cultures, smoking is a well-accepted means of socializing ${ }^{56}$ and tobacco products are even used to express gratitude. ${ }^{57}$ To have a better understanding of the high prevalence of tobacco use among males in the DPRK, it will be necessary to study the social, cultural, and economic contexts in the country. 
Table 1

Prevalence of smoking among selected countries located in Eastern Asia, Southeastern Asia, and Eastern Europe regions in 2020

(source: WHO FCTC report).

\begin{tabular}{|lllllllll|}
\hline \multirow{2}{*}{ Country } & \multicolumn{3}{c}{ Prevalence of Smoking } & \multicolumn{3}{c|}{ Prevalence of Daily Smoking } & \multirow{2}{*}{ Ratio of daily smokers among total smokers } \\
\cline { 2 - 6 } & Male & Female & Total & Male & Female & Total & \\
\hline Cambodia & 32.9 & 2.4 & 16.9 & 32.1 & 2.4 & 16.5 & 0.98 \\
\hline China & 50.5 & 2.1 & 26.6 & 44.4 & 1.6 & 23.2 & 0.87 \\
\hline Democratic People's Republic of Korea & 46.1 & 0 & 22 & 38.4 & 0 & 18.3 & 0.83 \\
\hline Japan & 29 & 8.1 & 17.8 & 26.9 & 7.3 & 16.4 & 0.92 \\
\hline Lao People's Democratic Republic & 50.8 & 7.1 & 27.9 & 46.9 & 7.1 & 25.8 & 0.92 \\
\hline Malaysia & 40.5 & 1.2 & 21.3 & 36.3 & 0.9 & 19 & 0.89 \\
\hline Mongolia & 49.1 & 5.3 & 27.1 & 45.4 & 4.5 & 24.8 & 0.92 \\
\hline Philippines & 40.3 & 5.1 & 22.7 & 33.9 & 3.6 & 18.7 & 0.82 \\
\hline Republic of Korea & 35.8 & 6.5 & 21.1 & 31.7 & 4.7 & 18.2 & 0.86 \\
\hline Russia & 46 & 14 & 29 & 44 & 11 & 26 & 0.9 \\
\hline Thailand & 37.7 & 1.7 & 19.1 & 33.4 & 1.38 & 16.9 & 0.88 \\
\hline Vietnam & 45.3 & 1.1 & 22.5 & 38.7 & 0.9 & 19.2 & 0.85 \\
\hline
\end{tabular}

It was interesting to see that the DPRK reported no female smokers at all in both 2018 and 2020. The prevalence of smoking among adolescent males, age from $13-15$, was $1.3 \%$ in the same reports. It is a good indicator in terms of public health as smoking could be more harmful to women and children. However, a question arises whether the stark difference in prevalence of smoking between men and women could be an indicator of gender equality in the society rather than cultural norms.

According to the WHO FCTC reports, smoking cigarettes was the only method of tobacco use in the DPRK. No other methods such as chewing tobacco or using the e-cigarette were reported. Not like some other countries that faced challenges to control e-cigarette smoking, ${ }^{58}$ this is a favorable condition to implement the tobacco control policy focusing only on cigarette smoking.

One of four video materials ran the story of how the nicotine patch was developed in the DPRK. ${ }^{46}$ It is notable that they succeeded in producing the new nicotine patch in the DPRK while the country is under strict international sanctions limiting its access to outside partners. Since the nicotine patch in the video was produced and distributed domestically only, neither its effectiveness nor safety can be verified according to the international standard. Nonetheless, the video demonstrates a commitment toward tobacco control, with researchers volunteering themselves for the clinical trials. The leader of the research team was later awarded the first prize in the national science and technology contest. The domestic production of the nicotine patch could become an important tool for the DPRK people to reduce tobacco use. ${ }^{59}$

Overall, the articles that included the DPRK data regarding tobacco use was scarce in number and depended upon extremely limited sources. Yet we were able to confirm that various anti-smoking activities were present in the DPRK while their impacts were not clearly shown in the literature nor in the media. According to the online media, the DPRK has hosted international meetings on the World No Tobacco Day (May 31st) every year at least from 2016 to 2019 , before the Covid-19 pandemic, to discuss tobacco control. There is a central smoking-cessation center in Pyongyang, the capital city, to provide people with education and multiple smoking-cessation products. Also, various public health interventions at the local and nationwide levels were discussed. In November 2020, the DPRK has adopted a new anti-smoking law at the Supreme People's Assembly. Even though the details of the law have not been openly disclosed, it was known to include strong regulations on smoking ban in public areas. ${ }^{42,43}$

There are two main limitations of the present study. First, as previous studies about the DPRK, sources for review were significantly limited. It was inevitable considering the DPRK's isolated status in the global society. Due to the lack of data, we were not able to run any statistical analysis. Second, even though we were able to collect meaningful information about tobacco control activities in the DPRK from the online media and its domestic scientific articles, we still do not know about effectiveness and validity of those activities. Furter studies are necessary to objectively evaluate the outcomes.

\section{Conclusions}

The current prevalence of tobacco use in the DPRK is relatively higher than global average with slight reduction over time.

There are promising signs that show the DPRK government's stewardship to promote population health by controlling tobacco use. Furthermore, the DPRK government has taken steps to implement the mandates of the FCTC including introduction of new laws, promotion of research, development of cessation aids, as well as public health campaigns.

Accurate evaluations on the DPRK's public health interventions to control tobacco use are necessary to develop new policies that will warrant high effectiveness in its unique social and cultural contexts. Close international cooperation is suggested to achieve the goal. 


\section{List Of Abbreviations}

WHO

World Health Organization

FCTC

Framework Convention of Tobacco Control

DPRK

Democratic People's Republic of Korea

\section{Declarations}

Ethics approval and consent to participate: Not applicable.

Consent for publication: Not applicable.

Availability of data and materials: The data that support the findings of this study are available from the WHO FCTC report that was prepared by the DPRK government. It can be found on the website: https://untobaccocontrol.org/impldb/wp-content/uploads/DPRKorea_2020_WHOFCTCreport.pdf.

Competing interests: The authors declare that they have no competing interests.

Funding: None.

Authors' contributions: HL reviewed selected materials, performed analysis, and wrote the manuscript. MK developed the search strategy and participated in manuscript writing. SY collected the scientific articles published in the DPRK and participated in analysis. KBP set up the research questions and participated in manuscript writing. All authors read and approved the final manuscript. All authors' contributions were significant and justifiable to obtain the authorship.

Acknowledgements: Not applicable

\section{References}

1. Samet JM. Epidemiology and the Tobacco Epidemic: How Research on Tobacco and Health Shaped Epidemiology. Am J Epidemiol. 2016;183(5):394-402. Doi:10.1093/aje/kwv156

2. Proctor RN. The history of the discovery of the cigarette-lung cancer link: evidentiary traditions, corporate denial, global toll. Tobacco Control. 2012;21:8791.

3. U.S. Department of Health and Human Services. The Health Consequences of Smoking-50 Years of Progress: A Report of the Surgeon General. Atlanta: U.S. Department of Health and Human Services, Centers for Disease Control and Prevention, National Center for Chronic Disease Prevention and Health Promotion, Office on Smoking and Health, 2014 [accessed 2021 May 30].

4. WHO. Tobacco. https://www.who.int/news-room/fact-sheets/detail/tobacco [accessed 2021 May 30].

5. Murray CJL, Forouzanfar MH, Gakidou E, et al. Smoking prevalence and attributable disease burden in 195 countries and territories, 1990-2015: a systematic analysis from the Global Burden of Disease Study 2015. The Lancet. 2017 May 13;389(10082):1885-1906.

6. IHME. http://www.healthdata.org/data-visualization/tobacco-visualization

7. WHO. WHO report on the global tobacco epidemic, 2019. Country profile: Democratic People's Republic of Korea.

https://www.who.int/tobacco/surveillance/policy/country_profile/prk.pdf

8. Amere GA, Nayak P, Salindri AD, Narayan KMV, Magee MJ. Contribution of Smoking to Tuberculosis Incidence and Mortality in High-Tuberculosis-Burden Countries. Am J Epidemiol. 2018; 187(9):1846-1855. DOI:10.1093/aje/kwy081

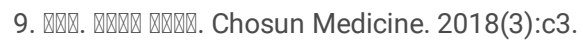

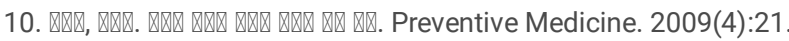

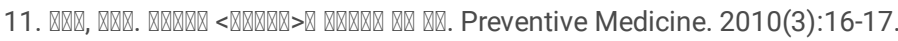

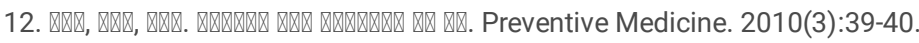

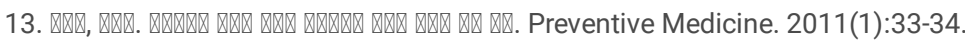

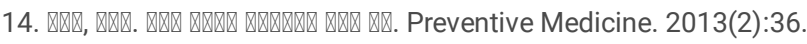

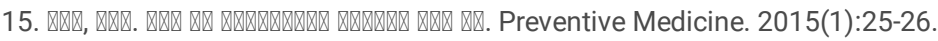

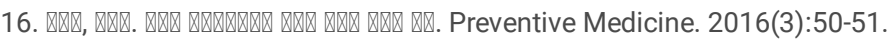

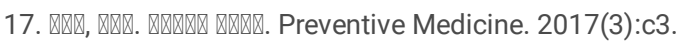

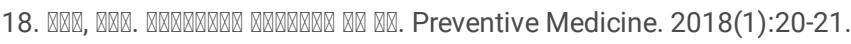

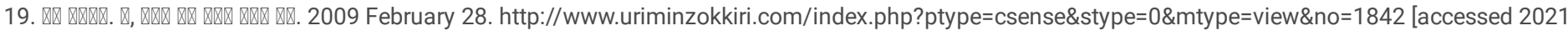
April 19]

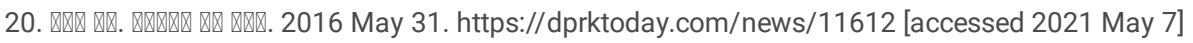

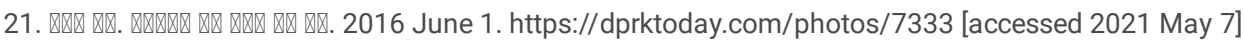




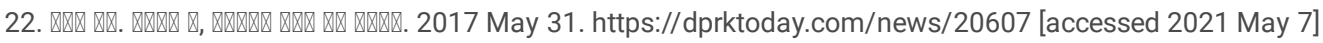

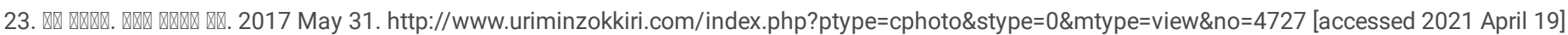

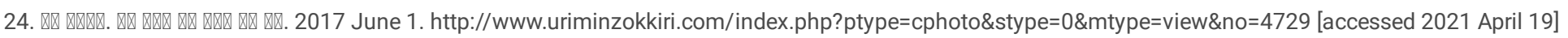

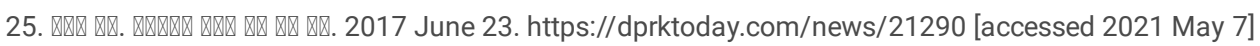

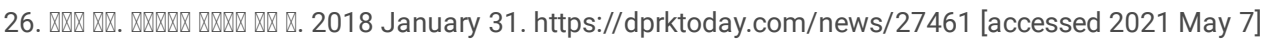

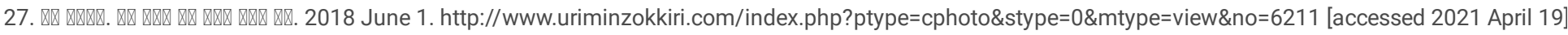

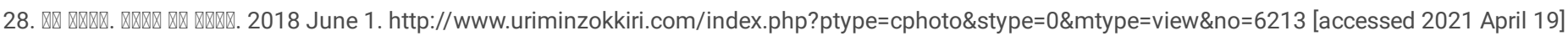

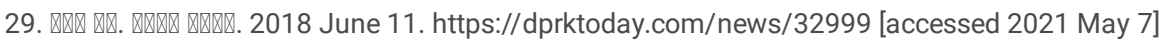

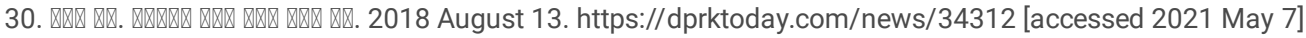

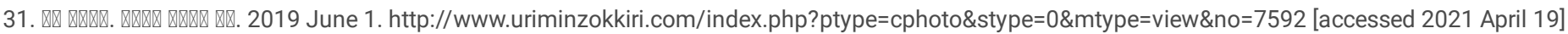

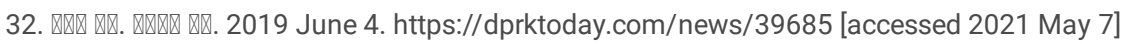

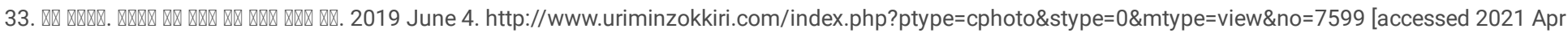
19]

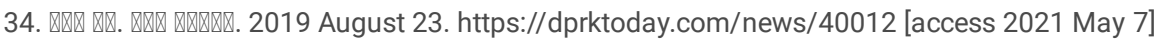

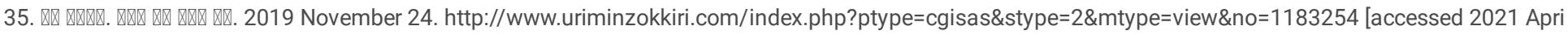
19]

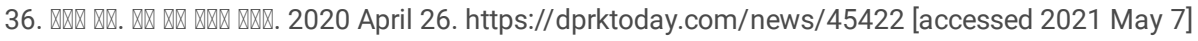

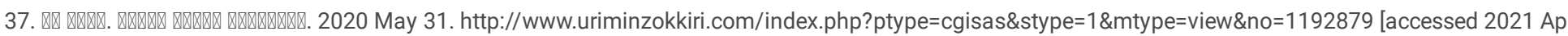
19]

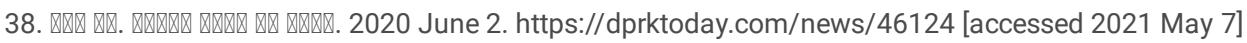

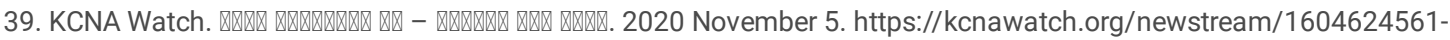

288746623/\%ea\%b8\%88\%ec\%97\%b0\%eb\%b2\%95\%ea\%b3\%bc-

\%ea\%b8\%b0\%ec\%97\%85\%ec\%86\%8c\%eb\%b2\%95\%ec\%88\%98\%ec\%a0\%95\%eb\%b3\%b4\%ec\%b6\%a9-\%ec\%b1\%84\%ed\%83\%9d-

\%ec\%b5\%9c\%ea\%b3\%a0\%ec\%9d\%b8\%eb\%af\%bc\%ed\%9a\%8c\%ec\%9d\%98-\%ec\%83\%81/ [accessed 2021 May 7]

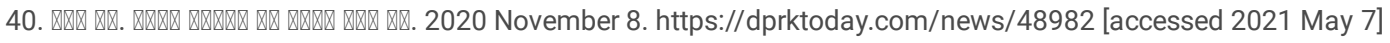

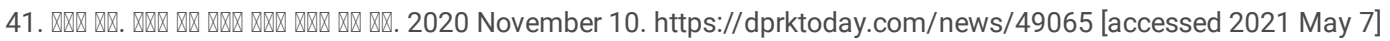

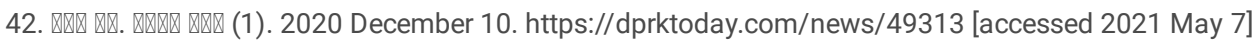

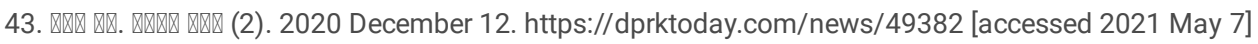

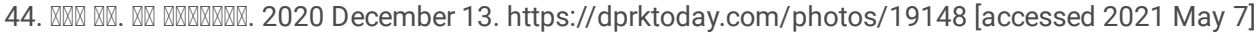

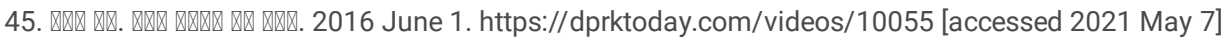

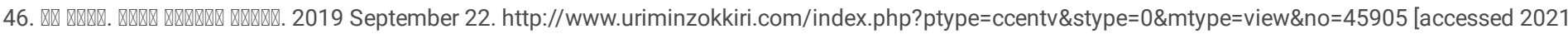

May 7]

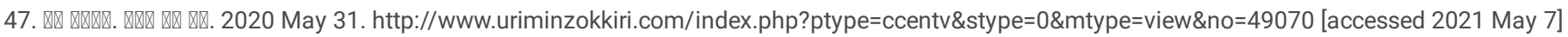

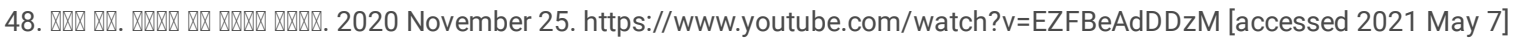

49. WHO FCTC. https://untobaccocontrol.org/impldb/wp-content/uploads/reports/dpr_Korea_2012_report.pdf [accessed 2021 May 7]

50. WHO FCTC. https://untobaccocontrol.org/impldb/wp-content/uploads/reports/dpr_korea_2014_report.pdf [accessed 2021 May 7]

51. WHO FCTC. https://untobaccocontrol.org/impldb/wp-content/uploads/DPR_Korea_2018_report.pdf [accessed 2021 May 7]

52. WHO FCTC. https://untobaccocontrol.org/impldb/wp-content/uploads/DPRKorea_2020_WHOFCTCreport.pdf [accessed 2021 May 7]

53. Tobacco Control Laws.

https://www.tobaccocontrollaws.org/files/live/Democratic\%20People's\%20Republic\%20of\%20Korea/Democratic\%20People\%27s\%20Republic\%20of\%20r \%20TC\%20Decree\%20No.\%201176.pdf [accessed 2021 May 7]

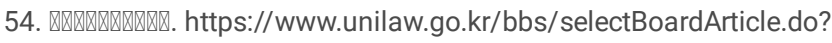

bbsld=BBSMSTR_000000000021\&bbsSubld=\&nttld=97\&bbsTyCode=BBST01\&bbsAttrbCode=BBSA02\&authFlag=Y\&pagelndex=3\&passwordConfirmAt=\& [accessed 2021 May 7]

55. Tobacco Control Laws.

https://www.tobaccocontrollaws.org/files/live/Democratic\%20People's\%20Republic\%20of\%20Korea/Democratic\%20People\%27s\%20Republic\%20of\%20 \%20TC\%20Summary\%20\%28through\%202006\%29.pdf [accessed 2021 May 7]

56. Schaefer DR, Adams J, Haas SA. Social networks and smoking: exploring the effects of peer influence and smoker popularity through simulations. Health Educ Behav. 2013;40(1 Suppl):24S-32S. doi:10.1177/1090198113493091

57. Huang LL, Thrasher JF, Jiang Y, Li Q, Fong GT, Quah AC. Incidence and correlates of receiving cigarettes as gifts and selecting preferred brand because it was gifted: findings from the ITC China Survey. BMC Public Health. 2012;12:996. Published 2012 Nov 17. Doi:10.1186/1471-2458-12-996

58. Benowitz NL, Goniewicz ML. The Regulatory Challenge of Electronic Cigarettes. JAMA. 2013;310(7):685-686. Doi:10.1001/jama.2013.109501

59. Fiore MC, Jorenby DE, Baker TB, Kenford SL. Tobacco dependence and the nicotine patch. Clinical guidelines for effective use. JAMA. 1992;268(19):26872694. 
Figures

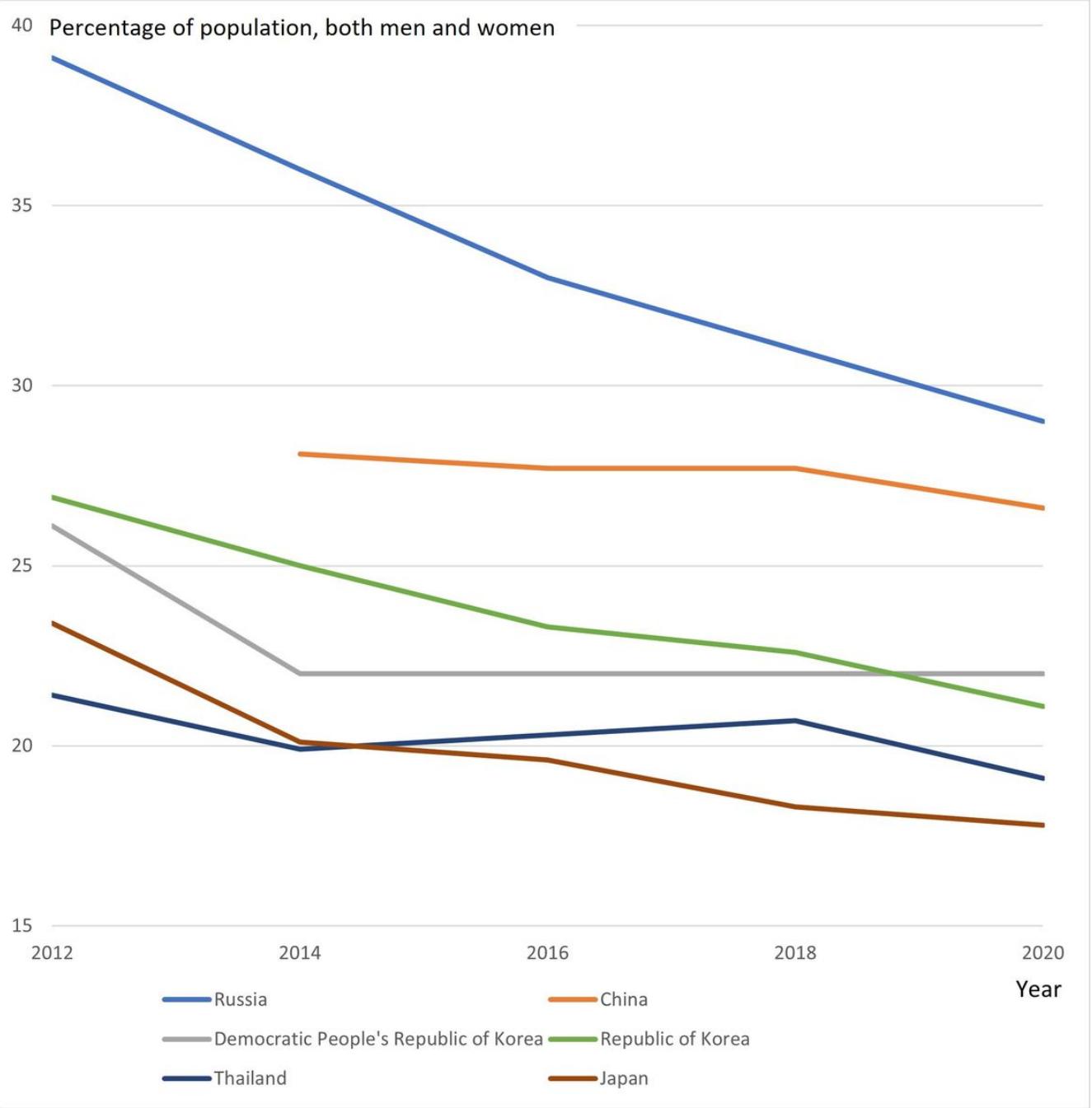

Figure 1

Prevalence of smoking among selected countries located in Eastern Asia, Southeastern Asia, and Eastern Europe regions from 2012 to 2020 (source: WHO FCTC report). 